\title{
Clinical Presentation and Follow Up of Patients with Mucopolysaccharidosis Type IVA (Morquio A Disease): Single Center Experience
}

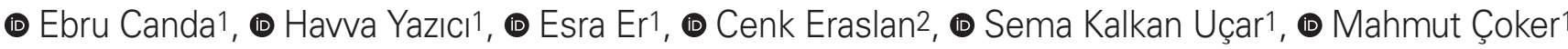 \\ ${ }^{1}$ Ege University Faculty of Medicine, Department of Pediatric, Division of Pediatrics Metabolism and Nutrition, Izmir, Turkey \\ 2Ege University Faculty of Medicine, Department of Radiology, Izmir, Turkey
}

\begin{abstract}
Aim: Mucopolysaccharidosis Type IVA (MPS IVA), Morquio A, is caused by the deficiency in lysosomal enzyme N-acetylgalactosamine-6-sulfate sulfatase. Multisystemic involvements include skeletal systems, pulmonary disease, valvular heart disease, hearing loss, mild hepatomegaly, corneal clouding, coarse facial features.

Materials and Methods: We retrospectively analyzed clinical and laboratory and follow up findings of our 25 patients with ministry for primary industries independent verification agency.

Results: Mean age of the patients was $14.9 \pm 7.05$ (5.5-36 years). Mean age at diagnosis was $7.3 \pm 6.2$ years ( 6 months- 31 years). Female: male ratio was $13 / 12$. All patients had skeletal manifestation and X-ray analysis demonstrated "dysostosis multiplex". Twelve patients (48\%) had cardiac valve disease. Twenty three (92\%) patients had corneal clouding, $15(60 \%)$ patients had hearing loss and $9(36 \%)$ had hepatomegaly. Six (24\%) patients were unable to walk. Mean follow up period is 7.4 years \pm 3.5 years $(3$ months-17 years). Four patients have not visit our clinical for last $\geq 3$ years. Three patients died during follow up.

Conclusion: MPS IVA is a severe disorder and is usually fatal in the second or third decade of life due to the complications of the disease. Early diagnosis of the patient became more important, because specific therapy with elasulphase alpha was approved recent years ago.

Keywords: MPS IVA, Morquio A, dysostosis multiplex, cardiac valve, corneal clouding
\end{abstract}

\section{Introduction}

Mucopolysaccharidosis Type IVA (MPS IVA or Morquio A disease; Online Mendelian Inheritance in Man 253000) was first described in 1929 by a pediatrician, L. Morquio in Montevideo (1). It is an autosomal recessive disorder caused by the deficiency of the lysosomal enzyme $\mathrm{N}$-acetylgalactosamine-6-sulfate sulfatase (GALNS) (2). In the absence of this enzyme, the degradation of keratin sulfate (KS) and chondroitin 6-sulfate (C6S) is blocked, which leads to intracellular accumulation of glycosaminoglycans (GAG) in the lysosomes of various tissues, especially bone and cornea
$(2,3)$. The incidence of MPS IVA is estimated to be 1:201.000 ranges among various populations from 1 in 76.000 live births in Northern Ireland to 1 in 640.000 live births in Western Australia (4-6). Affected infants seem normal at birth but will progress disease signs within a few years. Over $70 \%$ of patients with MPS IVA have initial clinical manifestations of skeletal features within the first 2-3 years of life (7). These include striking short trunk dwarfism, odontoid hypoplasia, pectus carinatum, kyphosis, gibbus, scoliosis, genu valgum, coxa valga, flaring of the lower ribs, hypermobile joints, and abnormal gait with a tendency to fall. Patients with MPS IVA have preserved intelligence (7). The other problems include pulmonary disease, valvular heart disease, hearing loss, mild 
hepatomegaly, corneal clouding, and coarse facial features (8). The clinical manifestations of the disease and resulting impaired mobility can reduce the patient's ability to perform activities of daily living (9). Diagnosis is typically based on clinical examination, skeletal radiographs, and the enzymatic activity of GALNS in blood cells or fibroblast $(7,10)$. GLNS gene located on chromosome 16q24:3, contains 14 exons $(11,12)$. The management of Morquio A syndrome has typically been supportive and symptom-based. Specific enzyme replacement therapy (ERT) has recently become available. In 2014, the use of recombinant human GALNS, elosulfase alfa, was approved in the European Union, Canada, United States, Australia, and Brazil for the treatment of Morquio A syndrome. Elosulfase alfa is administered intravenously onceweekly at a dose of $2.0 \mathrm{mg} / \mathrm{kg}$ (13). Here we present our cases to describe an overview of the clinical manifestations, diagnosis, and management of patients with MPS IVA

\section{Materials and Methods}

Twenty-five patients who were diagnosed with MPS IVA between 1995 and 2017 were included. Patients' demographical features including age, sex and age at diagnosis and height, weight, body mass index (BMI), height standard deviation score (SDS), weight SDS and BMI SDS levels were recorded. Ophthalmological examination, presence of skeletal involvements, adenoidal hypertrophy, hearing loss, organomegaly, pulmonary and cardiovascular complications, and surgical histories were noted. We collected the biochemical data to determine the function of the organs, GALNS enzyme levels, urine GAG and urine KS levels. Available radiological information also included. Sixminute walk test results were collected from the patients' records. Descriptive values of demographic and clinical parameters were analyzed.

\section{Results}

Mean age of the patients was $14.9 \pm 7.05$ years (range; 5.5-36). Mean age at diagnosis was $7.3 \pm 6.2$ years (range; 6 months-31 years). Female to male ratio was 13:12. Two patients were diagnosed at 1 to 3 years of age, 6 patients were diagnosed at 3 to 5 years of age, 13 patients were diagnosed at 5 to 10 years of age, and four of the patients were diagnosed at age more than 10 (Figure 1). Mean followup time was $7.4 \pm 3.5$ years (range; 6 months-17 years). Failure to thrive was detected in all patients at the time of diagnosis accept one patient who was diagnosed at the age of 6 months; she had no clinical signs, and detection of the enzyme level was performed because she had a brother with MPS IVA. When she was one year old, she had the skeletal manifestation, short trunk, and kyphosis and the other systems involvement appeared during follow-up. Mean height SDS was $-8.36 \pm 2.88$ (range; -13.5 to -3.54 ), mean weight SDS was $-3.4 \pm 1.1$ (range; from -5.5 to -1.8 ) and mean BMI SDS was $0.9 \pm 1.03$ (range; -0.96 to 3.04 ). Birth weights

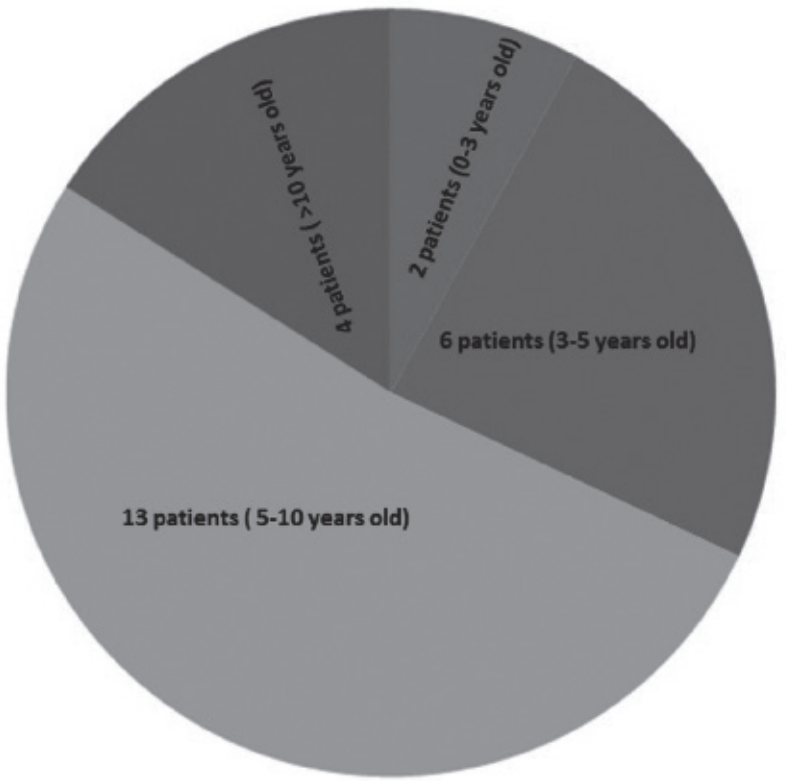

Figure 1. The ages of the patients at diagnosis

and heights of the patients were in normal range. All patients had urine GAG levels and enzyme activity of GALNS. Urine KS levels were available in 10 patients. Multiple sulphatase deficiency was ruled out for all patients. All patients had low enzyme activities of GALNS. Urine KS levels were increased in all 10 patients. The clinical and demographical details of the patients were summarized in Table I. All patients had skeletal manifestation including short trunk dwarfism, odontoid hypoplasia, pectus carinatum, kyphosis, gibbous, scoliosis, genu valgum, coxa valga, and hypermobile joint. X-ray analysis demonstrated "dysostosis multiplex" (DM) in all patients. Progression of anterior beaking, progressive kyphosis, platyspondyly and irregularities of the vertebral bodies were detected in all patients. The other clinical findings which were detected are corneal clouding, hearing loss, organomegaly, adenoid hypertrophy, cardiac valve disease and ventricular dysfunction. Clinical findings of the patients were detailed in Figure 2. Ten patients had recurrent pulmonary infections. Mild mental retardation was detected in $9(92 \%)$ patients. Twenty-three patients had corneal clouding, one of them had corneal opacities. One had the plan of corneal transplantation.

Twelve patients had cardiac valve disease. Seven of them had mitral valve insufficiency; two of them had aortic valve insufficiency. Two of them had both aorta and mitral insufficiency. One patient had left ventricular dysfunction and treated with medical therapy. The others had no medical therapy due to cardiac involvement accept recommendation endocarditis prophylaxis. Complete blood count, biochemical analysis for liver and renal functions were in normal range. Three patients had vitamin D insufficiency. Spinal MR investigation was performed in 13 of patients. All had foramen magnum stenosis, intervertebral disc protrusion, 


\begin{tabular}{|c|c|c|c|c|c|c|c|c|}
\hline $\begin{array}{l}\text { Patient } \\
\text { no }\end{array}$ & Gender & $\begin{array}{l}\text { Age/ } \\
\text { age at } \\
\text { diagnosis } \\
\text { (years) }\end{array}$ & $\begin{array}{l}\text { Follow-up } \\
\text { period } \\
\text { (years) }\end{array}$ & $\begin{array}{l}\text { Height } \\
\text { SDS }\end{array}$ & $\begin{array}{l}\text { Weight } \\
\text { SDS }\end{array}$ & $\begin{array}{l}\text { BMI } \\
\text { SDS }\end{array}$ & $\begin{array}{l}\text { Enzyme levels } \\
\mathrm{pmol} / \mathrm{mg} / \mathrm{h}(400- \\
2000){ }^{*} \mathrm{nmol} / \\
\mathrm{mg} / 17 \mathrm{~h}(45-249)\end{array}$ & $\begin{array}{l}\text { Clinical } \\
\text { findings }\end{array}$ \\
\hline 1 & $\mathrm{~F}$ & $16 / 6$ & 10 & -10.5 & -3.47 & 2.76 & $3^{*}$ & Coarse face, short stature, hepatomegaly, hearing loss, corneal clouding \\
\hline 2 & $\mathrm{~F}$ & $14 / 7$ & 7.5 & -6.5 & -3.5 & 0.14 & 13 & Coarse face, short stature, corneal clouding \\
\hline 3 & $\mathrm{~F}$ & $19 / 6$ & 13 & -5.06 & -2.24 & 1.05 & 13 & Coarse face, short stature, corneal clouding, adenoid hypertrophy \\
\hline 4 & M & $21 / 7$ & 7 & -11.5 & -4.50 & 1.5 & $1^{*}$ & Coarse face, short stature hepatomegaly, corneal clouding \\
\hline 5 & $\mathrm{~F}$ & $15 / 10$ & 9 & -9.78 & -5.07 & 0.08 & 2.8 & $\begin{array}{l}\text { Coarse face, short stature, hearing loss, corneal clouding adenoid } \\
\text { hypertrophy }\end{array}$ \\
\hline 6 & $\mathrm{~F}$ & $10 / 7$ & 9 & -5.39 & -2.24 & 0.58 & 20 & $\begin{array}{l}\text { Coarse face, short stature, hepatomegaly, corneal clouding, mild } \\
\text { retardation }\end{array}$ \\
\hline 7 & $\mathrm{M}$ & $8 / 3.5$ & 7 & -5.39 & -2.27 & 1.02 & $0^{*}$ & $\begin{array}{l}\text { Coarse face, short stature, hearing loss, corneal clouding, mild } \\
\text { retardation }\end{array}$ \\
\hline 8 & M & $21 / 1$ & 9 & -11.9 & -5.26 & 0.01 & $2^{*}$ & $\begin{array}{l}\text { Coarse face, short stature, hepatomegaly, hearing loss, corneal clouding, } \\
\text { adenoid hypertrophy }\end{array}$ \\
\hline 9 & $\mathrm{~F}$ & $11 / 5.5$ & 5.9 & -8.58 & -3.52 & 0.11 & 27.5 & $\begin{array}{l}\text { Coarse face, short stature, hearing loss, corneal clouding, mild } \\
\text { retardation }\end{array}$ \\
\hline 10 & $\mathrm{~F}$ & $24.5 / 2$ & 17 & -11.7 & -4.83 & 2.10 & $2.2^{*}$ & $\begin{array}{l}\text { Coarse face, short stature, hearing loss, corneal clouding, adenoid } \\
\text { hypertrophy }\end{array}$ \\
\hline 11 & $\mathrm{~F}$ & $13.5 / 4.5$ & 9 & -9.61 & -4.40 & 0.93 & $0.15^{*}$ & $\begin{array}{l}\text { Coarse face, short stature, hearing loss, mild retardation, adenoid } \\
\text { hypertrophy }\end{array}$ \\
\hline 12 & $\mathrm{M}$ & $14 / 7$ & 11 & -6.6 & -1.81 & 2.86 & 73 & $\begin{array}{l}\text { Coarse face, short stature, hearing loss, corneal clouding, mild } \\
\text { retardation, adenoid hypertrophy }\end{array}$ \\
\hline 13 & M & $8 / 3.9$ & 5.5 & -5.79 & -2.05 & 2.02 & 10 & $\begin{array}{l}\text { Coarse face, short stature, hearing loss, corneal clouding, mild } \\
\text { retardation, adenoid hypertrophy }\end{array}$ \\
\hline 14 & $\mathrm{~F}$ & $6 / 0.5$ & 6 & 3.54 & -2.05 & 0.11 & 35.2 & Coarse face, short stature, corneal clouding \\
\hline 15 & M & $11 / 3$ & 5.5 & -7.32 & -2.33 & 2.07 & 12.8 & Coarse face, short stature, hearing loss, adenoid hypertrophy \\
\hline 16 & $\mathrm{~F}$ & $12 / 7.3$ & 5 & -8.96 & -3.50 & 0.91 & 35 & $\begin{array}{l}\text { Coarse face, short stature, hepatomegaly, hearing loss, corneal clouding, } \\
\text { adenoid hypertrophy }\end{array}$ \\
\hline 17 & $\mathrm{~F}$ & $8 / 3.5$ & 5 & -6.08 & -2.41 & 0.76 & 40.9 & Coarse face, short stature, corneal clouding \\
\hline 18 & M & $21 / 12$ & 7 & -12.46 & -5.57 & 0.96 & $0^{*}$ & Coarse face, short stature, hepatomegaly, hearing loss, corneal clouding \\
\hline 19 & $\mathrm{~F}$ & $9.5 / 6$ & 4 & -6.94 & -3.30 & 0.26 & 14 & Coarse face, short stature, corneal clouding, mild retardation \\
\hline 20 & $\mathrm{~F}$ & $36 / 31$ & 4.5 & -12.10 & -4.69 & 0.4 & 0 & Coarse face, short stature, hepatomegaly, hearing loss, corneal clouding \\
\hline 21 & M & $12 / 6$ & 1 & -6.01 & -2.61 & 0.85 & 0 & Coarse face, short stature hepatomegaly, corneal clouding \\
\hline 22 & M & $5.5 / 5$ & 0.3 & -4.5 & -2.69 & 0.74 & 0 & Coarse face, short stature, hepatomegaly, corneal clouding \\
\hline 23 & M & $25 / 15$ & 10 & -13.5 & -4.90 & 0.01 & 16 & $\begin{array}{l}\text { Coarse face, short stature, hearing loss, corneal clouding, mild } \\
\text { retardation, adenoid hypertrophy }\end{array}$ \\
\hline 24 & M & $18 / 8$ & 10 & -11 & -4.20 & 0.84 & 34 & Coarse face, short stature, hearing loss, corneal clouding \\
\hline 25 & M & $15 / 6$ & 8 & -8.30 & -2.50 & 3.04 & 34 & Coarse face, short stature, corneal clouding, mild retardation \\
\hline
\end{tabular}

BMI: Body mass index, SDS: Standard deviation score, F: Female, M: Male

loss of vertebral corpus height, malformations of vertebral bodies, platyspondyly, peri odontoid tissue, and ligaments thickening. Four patients had cervical myelopathy. Three patients had spinal cord compression and decompressive surgery is planned. Six (24\%) patients were unable to walk, four (16\%) patients walk less than 200 m, 13 (56\%) patients walk between 200-400 $\mathrm{m}$ and one (4\%) patient walk between 400-800 m. Bone mineral density (BMD) results were available in 10 patients and 7 of them had osteoporosis. Mean lumbar vertebrae Z scores was -2.8 2.9 (range; -9.4- 


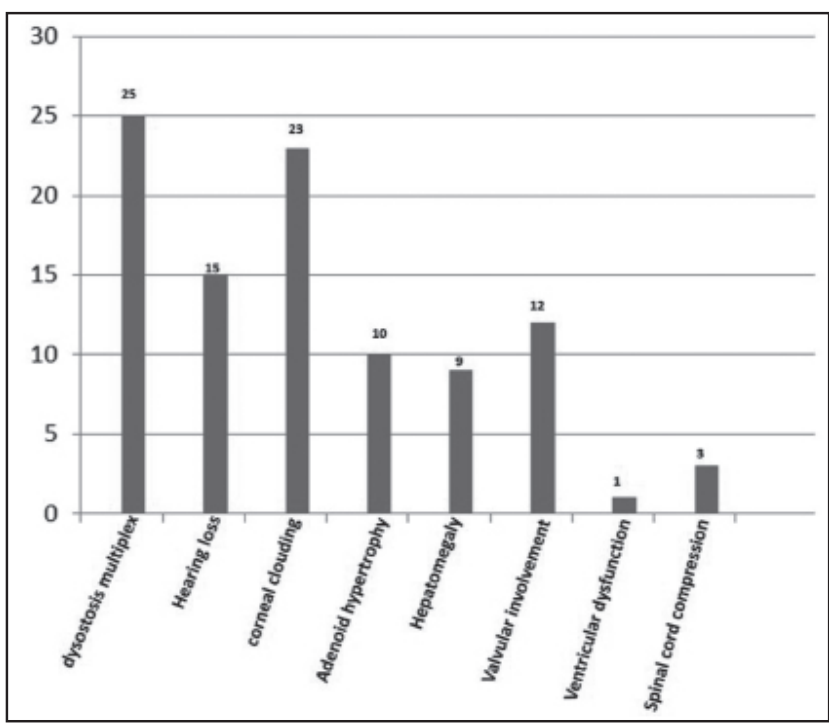

Figure 2. Clinical findings of the patients with mucopolysaccharidosis Type IVA

0.5 ) and mean neck of femur $Z$ scores was $-3.1 \pm 1.95$ (range; -5.1-0.2). Seven patients had undergone adenoidectomy. Four patients had knee operation, two patients had hip operation, and 5 patients had the history of inguinal hernia repair. Mean age was $7.2 \pm 4.4$ years (range; $3-16$ ) for adenoidectomy, $10.5 \pm 2.3$ years (range; $1.5-12$ ) for orthopedic surgery, and $3.3 \pm 0.9$ years (range; $2.5-5$ ) for inguinal hernia repair.

Mean follow-up period is $7.4 \pm 3.5$ years (range; 3 months -17 years). Four patients had not visit our clinical for more than 3 years. Three patients died during follow up. Two of them died due to the cardiopulmonary complications at the age 15 and 16. Other patient died due to respiratory insufficiency and infection while spinal cord decompression surgery was planned for him at the age of 17. Fourteen patients have been treated with enzyme elasulphase alpha. Mean period for ERT is $2 \pm 0.5$ years (range; 3 months -2.9 years).

\section{Discussion}

The incidence of MPS IVA ranges among various populations from 1 in 76.000 live births in Northern Ireland to 1 in 640.000 live births in Western Australia (4-6). The higher incidence for Turkey is expected because of the high incidence of consanguinity marriages however we do not have a registration system for MPS IVA patients in our country. Over $70 \%$ of the patients with MPS IVA have initial clinical manifestations of skeletal features within the first 2-3 years of life (7). In our study, all patients had skeletal involvement. The common initial symptoms of our patients were short stature and gait disturbance and all have skeletal manifestations; as short trunk dwarfism, pectus carinatum, kyphosis, gibbous, scoliosis, genu valgum, coxa valga, hypermobile joint.

As reported by Montaño et al (7), musculoskeletal findings are a significant observation in patients with MPS
IVA. An important component of the musculoskeletal manifestations in patients with MPS IVA is DM. All our patients showed the characteristics of DM. Progression of anterior beaking, progressive kyphosis, platyspondyly and irregularities of the vertebral bodies were detected. One patient was diagnosed at the age of 6 months, she had no clinical signs, and detection of the enzyme level was performed because she had a brother with MPS IVA. Although the clinical manifestations of skeletal systems started in early years of life, in our study 8 (32\%) patients had the diagnosis of MPS IVA before the age 5 . The one who was diagnosed at 6 months of age had skeletal manifestation when she was one years old. Diffuse corneal clouding is the most common ocular finding in MPS IVA. Photophobia is associated with stromal corneal clouding which is usually not severe. Retinopathy may occur (14). Couprie J et al. (14) investigated the ocular manifestations in patients with MPS IVA; the most common ocular manifestation was corneal opacification, astigmatism, and punctate cataract. Ophthalmological follow-up is recommended to detect potentially curable complications such as astigmatism or lens opacities (14). Glaucoma or ocular hypertension seems to be unusual in MPS IVA (15). In our study 23 (92\%) patients had corneal clouding, none of them underwent eye surgery such as optical correction but one patient had corneal opacities. All forms of MPS, reduction in hearing can be attributed to multiple causes. Conductive hearing loss can be present due to recurrent upper respiratory tract infection. Most patients with MPS IVA have a mixed hearing loss; combination of a conductive element and sensorineural element (15). Hearing problems can become apparent by the end of the first decade of life (16). In our study 15 (25\%) patients had hearing loss. Seven of the patients had hearing loss before the age of 10. Generally, dermatan sulphate deposition in the MPS syndromes results cardiac valve problems. However, KS and C6S are both found in normal cardiac valves and according to this, cardiac valve involvement found in MPS IVA patients (17). Mild mitral or aortic valvular disease is common while myocardial thickening, systemic and pulmonary hypertension, is rare. Bacterial endocarditis prophylaxis is advised for the MPS IVA patient with cardiac abnormalities (18). In our study 12 (48\%) patients had cardiac valve disease. Similar to the literature most common valve insufficiency was in mitral or aortic valves. One patient had left ventricular dysfunction. The digestive system can be affected in patients with MPS IVA. According to the data of the International Morquio A registry which is conducted by the International Morquio Organization, some patients with MPS IVA had a hernia as their initial and current symptoms (7). In our study 5 of the patients had the history of inguinal hernia operation between the age of 2.5-5 years. Nelson et al. (19) reported hepatomegaly in their patients with MPS IVA, and was reported as an initial and current symptom in the International Morquio A Registry (7). We detected hepatomegaly in 9 patients. All our patients had normal liver functions. Suspicion of MPS IVA may be supported 
by quantitative and/or qualitative testing of urinary GAG levels demonstrating increased levels and presence of $K S$, but diagnosis requires confirmation of GALNS deficiency in white blood cells or fibroblasts, or mutation analysis showing the presence of pathogenic mutations in both alleles $(20,21)$. Enzyme activities of GALNS of all our patients were low. Urine KS analysis was available in 10 patients and all of them had elevated KS. We could not perform genetic analysis of our patients. Multiple sulphatase deficiency was ruled out in all patients. Endurance and functional capacity which is important outcome for MPS IVA patients, may be measured by the six-minute walk test (6MWT), which is simple and standardized measure of endurance (society AT, ATS statement: guidelines for the 6MWT A-11). In our study $6(24 \%)$ patients were unable to walk, four $(16 \%)$ patients walk less than 200 m, 13 (56\%) patients walk between 200$400 \mathrm{~m}$ and one (4\%) patient walk between 400 and $800 \mathrm{~m}$. Maintenance of functional capacity and mobility are likely to improve quality of life of the patients with MPS IVA.

One of the most important and difficult aspect of this care is the management of airway. To prevent frequent respiratory infections, sleep apnea and breathing difficulty, the registry data indicated that tonsillectomy and adenoidectomy were performed at an early stage (the mean age is around 5 years) (7). In our study 9 patients had adenoid hypertrophy and 7 patients underwent adenoidectomy; unlike the literature mean age of adenoidectomy was around 10 years. The affected MPS IVA patients often require surgical procedures in neck, hip, knee, and leg regions in the first decade (7). Our findings were also similar to the literature. Orthopedic complications are the most critical issues for MPS IVA patients. Surgical interventions such as cervical fusion, decompression of the spinal cord, hip replacement are often required $(7,22)$. None of our patients underwent surgery for spinal cord involvement. Although in three patients we planned spinal surgery, one patient died before the operation due to respiratory insufficiency and infectious complications and other two did not accept surgery. Kecskemethy et al. (23) showed that the lateral distal femur is the most feasible site to measure BMD in patients with MPS IVA. In our study, we have BMD results of 10 patients. We also think that because of the severe skeletal manifestations whole body mineral density should be performed. Davison et al. (24) demonstrated that central nervous system may not be entirely spared in MPS IVA as previously thought. Cognitive abnormalities and attention difficulties were reported. In our study 9 patients had mild retardation. We think that this finding may be result of social isolation and severe skeletal manifestation. Our study contains large number of MPS IVA patients from a single center and we presented our experience from a long survival period. In this study fourteen patients treated with enzyme elosulfase alpha. Mean period for ERT is $2 \pm 0.5$ years (range; 3 months- 2.9 years). Further studies with large number of patients may give us an opinion for the response to ERT in our region. Also after performing the gene analysis of the patients we may able to discuss the genotype and phenotype correlation of our patients.

\section{Conclusion}

MPS IVA is a severe progressive systemic skeletal disorder and is usually fatal in the second or third decade of life due to the complications. The disease has heterogeneous and progressive nature. Ideally, management should be centralized in major centers with access to all medical specialties. After the approval of the specific therapy with elosulfase alpha, early diagnosis of the patient became more important.

\section{Ethics}

Informed Consent: Consent form was filled out by all participants.

Peer-review: External and internal peer-reviewed.

\section{Authorship Contributions}

Surgical and Medical Practices: E.C., H.Y., E.E., Concept: M.Ç., S.K.U., Design: M.Ç., S.K.U., Data Collection or Processing: E.C., H.Y., E.E., C.E., Analysis or Interpretation: E.C., M.Ç., S.K.U., Literature Search: E.C., H.Y., E.E., C.E., Writing: E.C., M.Ç., S.K.U.

Conflict of Interest: No conflict of interest was declared by the authors.

Financial Disclosure: The authors declared that this study received no financial support.

\section{References}

1. Morquio L. Sur une forme de dystrophie osseuse familiale. Bull Soc Pediatr Paris 1929;27:145-52.

2. Dorfman A, Arbogast B, Matalon R. The enzymatic defects in Morquio and Maroteaux-Lamy syndrome. Adv Exp Med Biol 1976;68:261-76.

3. Glössl J, Kresse H. Impaired degradation of keratan sulphate by Morquio A fibroblasts. Biochem J 1982;203:335-8.

4. Meikle PJ, Hopwood JJ, Clague AE, Carey WF Prevalence of lysosomal storage disorders, JAMA 1999;249-54.

5. J Nelson. Incidence of the mucopolysaccharidoses in Northern Ireland. Hum Genet 1997;355-8.

6. Nelson J, Crowhurst B, Carey L. Greed, Incidence of the mucopolysaccharidoses in Western Australia. Am J Med Genet 2003;310-3.

7. Montaño AM, Tomatsu S, Gottesman GS, Smith M, Orii T. International Morquio A Registry: clinical manifestation and natural course of Morquio A disease. J Inherit Metab Dis 2007;30:165-74.

8. Northover H, Cowie RA, Wraith JE. Mucopolysaccharidosis type IVA (Morquio syndrome): a clinical review. J Inherit Metab Dis 1996;19:357-65.

9. Tomatsu S, Okamura K, Taketani T, et al. Development and testing of new screening method for keratan sulfate in mucopolysaccharidosis IVA. Pediatr Res 2004;55:5927. 
10. Hendriksz CJ, Lavery C, Coker M, et al. Burden of disease in patients with Morquio A syndrome: results from an international patient-reported outcomes survey. Orphanet J Rare Dis 2014;9:32.

11. Masuno M, Tomatsu S, Nakashima $Y$, et al. Mucopolysaccharidosis IV A: assignment of the human $\mathrm{N}$-acetylgalactosamine-6-sulfate sulfatase (GALNS) gene to chromosome 16q24. Genomics 1993;16:777-8.

12. Morris CP, Guo XH, Apostolou S, Hopwood JJ, Scott HS Morquio A syndrome: cloning, sequence, and structure of the human $\mathrm{N}$-acetylgalactosamine 6-sulfatase (GALNS) gene. Genomics 1994;22:652-4.

13. Hendriksz CJ. Elosulfase alfa (BMN 110) for the treatment of mucopolysaccharidosis IVA (Morquio A Syndrome). Expert Rev Clin Pharmacol 2016;9:1521-32.

14. Couprie J, Denis P, Guffon N, et al. Ocular manifestations in patients affected by Morquio syndrome (MPS IV). J Fr Ophtalmol 2010;33:617-22.

15. Hendriksz CJ, Al-Jawad M, Berger KI, et al. Clinical overview and treatment options for non-skeletal manifestations of mucopolysaccharidosis type IVA. J Inherit Metab Dis 2013;36:309-22.

16. Bredenkamp JK, Smith ME, Dudley JP, etal. Otolaryngologic manifestations of the mucopolysaccharidoses. Ann Otol Rhinol Laryngol 1992;101:472-8.

17. Dangel JH. Cardiovascular changes in children with mucopolysaccharide storage diseases and related disorders--clinical and echocardiographic findings in 64 patients. Eur J Pediatr 1998;157:534-8.

18. Tomatsu S, Montaño AM, Oikawa H, et al. Mucopolysaccharidosis type IVA (Morquio A disease): clinical review and current treatment. Curr Pharm Biotechnol 2011;12:931-45.

19. Nelson J, Thomas PS. Clinical findings in 12 patients with MPS IV A (Morquio's disease). Further evidence for heterogeneity. Part III: Odontoid dysplasia. Clin Genet 1988;33:126-30.

20. Wood TC, Harvey $K$, Beck $M$, et al. Diagnosing mucopolysaccharidosis IVA. J Inherit Metab Dis 2013;36:293-307.

21. Tomatsu AM, Montaño T, Nishioka MA, et al. Mutation and polymorphism spectrum of the GALNS gene in mucopolysaccharidosis IVA (Morquio A). Hum Mutat 2005;26:500-12.

22. Montaño AM, Tomatsu $S$, Brusius $A$, Smith $M$, Orii $T$. Growth charts for patients affected with Morquio A disease. Am J Med Genet 2008;15:1286-95.

23. Kecskemethy HH, Kubaski F, Harcke HT, Tomatsu S. Bone mineral density in MPS IV A (Morquio syndrome type A). Mol Genet Metab 2016;117:144-9.

24. Davison JE, Kearney S, Horton J, et al. Intellectual and neurological functioning in Morquio syndrome (MPS IVa). J Inherit Metab Dis 2013;36:323-8. 